null • Business of Knowing

\title{
Historical Choices and Knowledge Production
}

Shawn J. Martin ${ }^{1}$

${ }^{1}$ Dartmouth College

Published on: Aug 16, 2021

DOI: $10.21428 / 6 \mathrm{ffd} 8432.5 \mathrm{ebdd} 587$

License: Creative Commons Attribution 4.0 International License (CC-BY 4.0). 
Should the Infrastructure of knowledge production be exclusionary? If not, then who should be included? Though we continue to ask these questions in the twenty-first century it is not the first time that we have answered them. In fact, within the United States we asked and answered them over one hundred years ago when scholars were first working to formalize the institutions of scholarly publishing. To imagine what the future of scholarly communication might look like, we can examine the choices of the past and envision an alternative path. This essay is a thought exercise focusing on three critical points in the history of the scientific publishing system, particularly in the U.S., including the foundations of scientific societies in America, the institutionalization of science in the late nineteenth-century U.S., and the measurements of these preexisting trends developed in the mid twentieth century. As the nineteenth-century German philosopher and politician Friedrich Schlegel once declared, "the historian is a prophet looking backwards." This essay is an attempt to practice the kind of prophecy Schlegel was discussing, and the hope is for us to use that history to imagine a better scholarly communication system.
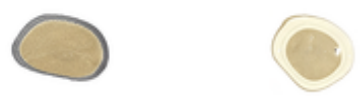

The origins of specialized scientific publishing began in seventeenth-century England, a society where a small number or people controlled a vast amount of wealth, some of whom also took an interest in scientific discovery because they had the leisure to do so. Many of these scientifically curious and leisured people were involved in the creation and governance of the Royal Society In the seventeenth century. Steven Shapin in his book A Social History of Truth (1995) argued that only "gentlemen" or people of a social class who society believed could be trusted to tell the truth were deemed worthy of membership in the Royal Society. There was, however, another tradition discussed by Pamela Long in Artisan/Practitioners and the Rise of the New Sciences (2011) in which guilds and craftsmen shaped scientific development in Europe. Over time, the Royal Society model eventually became the more dominant one, meaning that lower social status people had less influence in governance of journals and the scientific organizations that published them.

Long's model, however, might have had a chance in the American colonies. The American Philosophical Society, though modeled in some ways on the Royal Society, was a very different kind of organization. Founded in Philadelphia by Benjamin Franklin, the American Philosophical Society's initial members were not aristocrats 
and tended to come from well-to-do merchant families and, perhaps as a result, had more practical aspirations for America's first scientific society. In the first issue of the organization's journal, the Transactions of the American Philosophical Society (1769), its introduction states, "knowledge is of little use when confined to mere speculation: But when speculative truths are reduced to practice... knowledge then becomes really useful" (pages i - ii). In other words, knowledge must have practical application for it to be truly useful.

The question left unresolved here, however, was the meaning of practical application. Is literature useful, or are the arts useful? Many of the members of the American Philosophical Society would have believed that they were, but the concept of utility evolved over time in the United States in ways that would not be fully realized until the nineteenth century.

America in the mid to late nineteenth century was a country that was becoming heavily industrialized and where, aside from scattered attempts at creating organizations to promote science, there was not nearly the kind of social infrastructure present in most European countries. Alexander Dallas Bache (1806-1867) - the great-grandson of Benjamin Franklin, nephew of the Vice-President of the United States (George Dallas), and a member of the American Philosophical Society - had a career as a scientist, government administrator, and university professor. Bache also wanted to create institutions similar to those in Europe. Bache and his circle of colleagues took these two exiting beliefs present in the scientific community (that only certain people should be able participate in scientific societies and that science needed to be "useful") and built upon them to create America's first scientific institutions.

Bache and his supporters sought to create a kind of scientific aristocracy, similar in some ways to what could be found in Europe at the time. Within this "aristocracy," only the people that Bache and his close confidants wished to be included could be included, and the industrial application of scientific discoveries was valued more than less commercially viable innovations. Bache's friend Joseph Henry, the first secretary of the Smithsonian Institution, was perhaps most explicit in his eagerness for exclusion of certain kinds of people. Henry wrote to Bache in 1838, that it was essential Bache and his friends take greater control over the organization of science in the United States because, "otherwise third and fourth rate men would soon control the affair and render the whole abortive and ridiculous [emphasis Henry's]". 1 Bache himself stated that the purpose of American science should be, "increased production, whether in agriculture or manufactures," $\underline{2}$ and Bache went on to help found the American 
Association for the Advancement of Science, America's first scientific professional society, as well as the American Academy of Science. Overall, Bache and his circle of close colleagues (like Henry) eventually succeeded in their aims of concentrating scientific organization by utilizing government patronage, connections at the influential journals of the time, and their positions within scientific societies. Their motives, ostensibly, were to protect the scientific system from fraud; yet, it also worked to encourage the exclusion of certain voices from the scientific system, and may serve as a cautionary note that whenever alternate voices (like snake-oil salesmen) are excluded, often so are other voices that do not look like the people who are working to protect the public (in this case white men from a certain social class).

Over one hundred years later, Robert Merton, a sociologist studying the structures of scientific power was able to observe this concentration of power more objectively. In the 1960s, Merton noticed what he called the "Matthew Effect" in American scientific culture in which only well-known scientists were reaping the rewards of scientific publishing, rewards, and other forms of academic merit. Such evidence of disparate outcomes in American science might have been a turning point when people changed the system of knowledge production in the United States. Yet rather than countering or attempting to advocate for a different outcome of demonstrated inequality within the scientific scholarly communication system, Merton's colleague, Eugene Garfield, set out to measure the Matthew effect mathematically. Garfield calculated a measure by adding the number of citations to specific articles and dividing that number over the number of years that article was available. According to Garfield, this measurement could show the "impact" of an article in the field and show if certain scholars were more influential than others. Garfield's work formed the foundation of what is now known as the impact factor. The identification and naming of the "Matthew Effect" could have served as a pivotal point for advocating against such feedback loops in scholarly communication. And yet, it instead brought about the all-too-pervasive impact factor, used today to further reify an aristocracy of science.

Garfield was measuring Merton's observation. Bache was building on historical precedents set by the Royal Society and the American Philosophical Society. Overall, the result of these historical choices has resulted in a scholarly communication system that one could argue is designed to reward a select group of people chosen by a small number of individuals within a system of institutionalized scientific creation and distribution mechanisms (academic societies, publishers, and journals). 
Given this situation, how might it be possible to correct the decisions that have been made in the past?

First, and perhaps most important, it is essential to recognize that despite many positive aspects of the scientific and scholarly publication system, it has also built within it a process that was meant to exclude people. Joseph Henry, Bache's friend, sought to dismiss "third and fourth rate men" from participating in the practice of science. In Henry's own mind, he was protecting scientific integrity and excluding fraud within the system. At the same time, Henry was ensuring that only people like himself and Bache could participate in creation and dissemination of scientific knowledge.

Second, rather than using the impact factor as a method of quality, it should be used to measure the opposite; de facto, the impact factor measures inequality of academic rewards. Eliminating the impact factor as an indicator of research quality, however, would only be the beginning. The bigger question is how we can ensure that "third and fourth rate" men, women, and non-binary persons from backgrounds not as privileged as Bache are an integral part of the scholarly communication system.

Appropriate directions for moving forward have already been suggested in Kathleen Fitzpatrick's (2019) book, Generous Thinking. Fitzpatrick envisions a higher education ecosystem that is inclusive of all individuals, encompassing those in the larger community who may disagree with the expert opinions of those within the academy that creates "an ongoing, shared conversation, a conversation that has the potential to shape our collective experiences of the world" (p. 81). Fitzpatrick has even gone so far as to put some of these ideas into practical action. Before the publication of Generous Thinking, the Humanities Commons (https://hcommons.org/), a project Fitzpatrick worked on for the Modern Language Association, has put together an open repository that archives work of humanities scholars from a variety of professional scholarly associations. Furthermore, Fitzpatrick and Rebecca Kennison described in a white paper written prior to Generous Thinking's publication (Fitzpatrick, K. \& Kennison, R. (2017). Altmetrics in Humanities and Social Sciences. Humanities Commons.

http://dx.doi.org/10.17613/M6MW28D5J.), a project to implement "Humane Metrics," that endeavors to measure the contributions scholars make to society that are in line with some of the values that Fitzpatrick later articulated in Generous Thinking.

Only by recognizing our history and bettering the deliberate choices made over time can the undemocratic social structures that produce knowledge in the U.S. (and 
beyond it) become truly open and equitable. The ideas discussed in Generous Thinking is likely only a series of first steps that would need to be taken. Nonetheless, restructuring higher education to be a more inclusive, public facing, and generous system, would be one way to begin undoing the compounded historical errors of the past.

\section{0 read more essays in the "Business of knowing" summer series $\square$}

\section{Footnotes}

1. Letter from Joseph Henry to Alexander Dallas Bache, August 9, 1838 from the Joseph Henry Papers at the Smithsonian Institution. $\_$

2. From the Journal of the Franklin Institute in 1842, page $380 . \subseteq$ 